\title{
3q29 microdeletion syndrome
}

INSERM

\section{Source}

INSERM. (1999). Orphanet: an online rare disease and orphan drug data base. 3929 microdeletion syndrome. ORPHA:65286

3 q29 microdeletion syndrome is a recurrent subtelomeric deletion syndrome with variable clinical manifestations including intellectual deficit and dysmorphic features. 